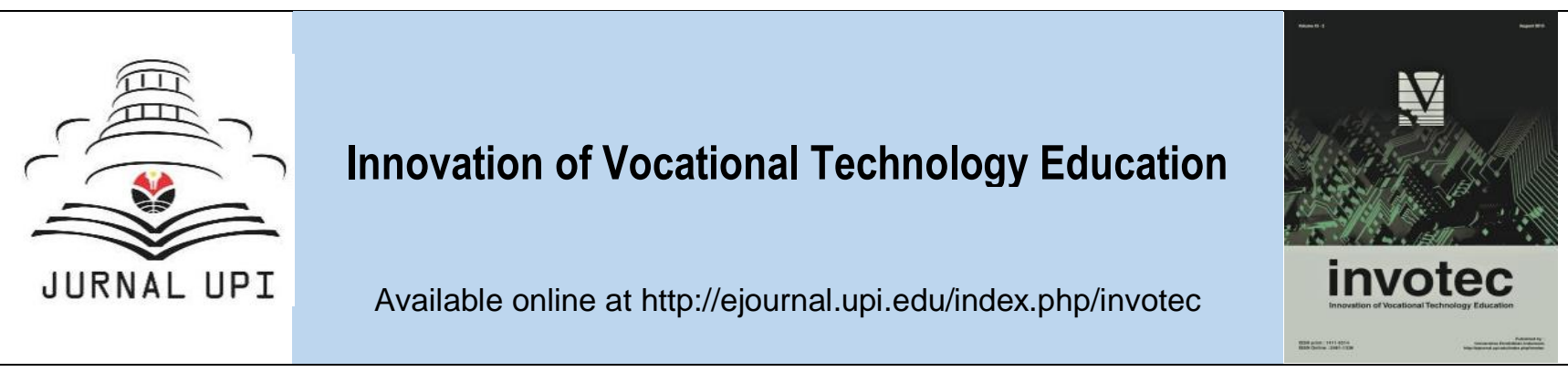

\title{
Gameplay Development of "Power Egg" As Interactive Learning Media of Arithmetic and Motoric Exercises for Elementary School Students
}

\author{
Wibisono S. Wardhono, I. Arwani \& M. I. C. S. Napitu \\ Brawijaya University, Indonesia
}

\section{ARTICLE INFO}

Article history:

Received 27 March 2017

Received in revised form 20 April

2017

Accepted 12 Mei 2017

Available online 31 August 2017

Keywords:

power egg,

interactive learning media,

arithmetic material

Corresponding author:

wibiwardhono@ub.ac.id
A B S T R A C T

Difficulties of learning mathematics, especially basic arithmetic like addition, subtraction, multiplication and division, most commonly found in children of elementary school. The material covering basic arithmetic addition, subtraction, multiplication and division began to be taught to children aged 6-9 years that is between grades $1 \mathrm{st}$ to $3 \mathrm{rd}$ of elementary school. The research's goals are developing interesting gameplay and interactive games as media learning of arithmetic for elementary school students in grade 1st to 3rd. Development of gameplay is expected to increase the interest of elementary school students on the concept of arithmetic and it will have implications for the success of teaching and learning arithmetic concepts for students. "Power Egg" is an interactive educational game. The game is designed based on the needs of gameplay by adding motoric exercises with the utilization of Kinect VR technology as input media. The game users target was Elementary Schools Students grade 1st to 3rd. The results of game testing showed that all students enjoy the games and $96 \%$ of students want to try the game again. After playing this game, the evaluation results of arithmetic material tested to thirty elementary school students showed an increase up to $8.8 \%$ compared to the evaluation before the students run the game.

\section{Introduction}

Difficulties of learning mathematics most commonly found in children of elementary school, however, the subjects of mathematics remain to be studied as a means to solve problems in everyday life (Fitriyeni, 2013). The material covering basic arithmetic addition, subtraction, multiplication and division began to be taught to children aged 6-9 years that is between grades 1st to 3rd of elementary school. On the other hand, the children at that age start likes to move (Hervira and Yuni, 2012). As an effort to support the delivery of material, arithmetic learning tool can be implemented in the form of video games (Castellar, et. al. 2015).

The exploration of motivational aspects of digital games showed that a game should present an obvious and compelling goal. There was a discrepancy between the game goal and the learning goal. Solution to this learning-outside-gameplay problem is designing fantasy that depends on the practice of skills, and vice versa, like the game treasure hunt. 
In order to achieve the expected goals, a game requires gameplay as rule's design of the game. One framework or development framework gameplay is the approach of MDA (Mechanics, Dynamics and Aesthetic) framework as a formal approach to understand the suitability of game design and technical implementation (Hunicke, at al. 2004). Game "Power Egg" was developed based on the needs to design and build a game that can solve the problems of children who do not like math that utilize Kinect technology as an input medium. The combination of games with input in the form of hand gestures is expected to have implications train motoric movements and add fun value to the game.

The research's goals are developing interesting gameplay and interactive games as media learning of arithmetic for elementary school students in grade 1st to 3rd, measure the gameplay's performance of the game by the parameters of usability, balance and fun and also the game effects to the learning outcomes.

\section{Method}

Game "Power Egg" is a mathematical education game which is devoted to children grades 1st to 3rd at elementary school. The first mathematics lesson in Indonesia formally learned by students at the 1st grade. 1st grade students have a great opportunity to like or dislike math. Grade 1st to 3rd of elementary School were given a lesson on the calculation of addition, subtraction, multiplication and division basis in order to continue to the next level (Hervira and Yuni, 2012.

Data collected by the expert interviews from teachers at SDN Penanggungan Malang, through playtesting and also the pre and post testing to students. Data needed in this research are: problems of math for grades 1st to 3rd of Elementary School. The level of the student's ability to mathematics lesson, dan Effect of game "Power Egg" based on the level of student's ability. Game design is the process of designing a game that aims to give a general overview to the user on the concept of the games that will be created. This game is designed using an iterative methodology with a rapid prototyping shown in Figure 1.

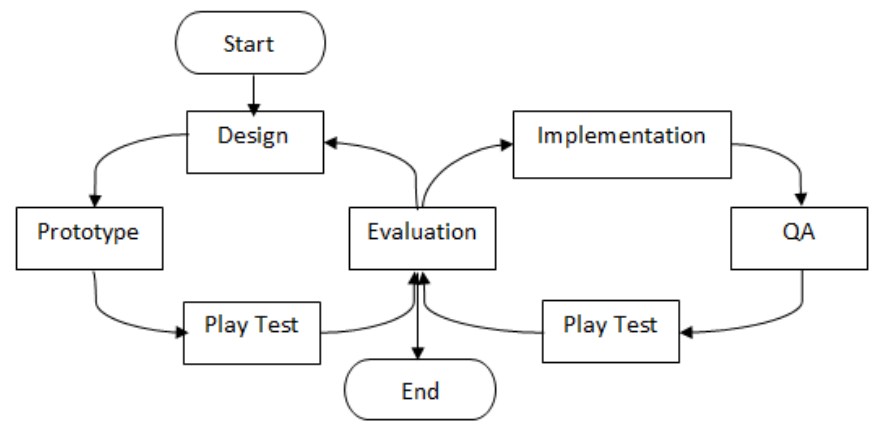

Figure 1. Iterative methodology with a rapid prototyping.

Game Interface Design at the game "Power Egg" includes display the 'Home' menu that contains Title Game, Settings button, about and the Play button to start the game. The second display is a 'Select grade' to choose players grade; 1st, 2nd or 3rd. The third display shows the level option to finish the game. The fourth display is gameplay that contains several game interaction buttons that includes a Pause button, reset, and objects such as eggs and scales.

The design of the game includes the following elements: Description of Game; Game Power Egg tells of a boy named Leo who wants to help her mother shopping eggs. Leo mother gave money to Leo to buy eggs with the correct change, so Leo had to gauge how many eggs you have to be purchased in order to fit the number of egg weight. In this game players play as Leo whose job is to save the insert eggs into the appropriate weight scales needed. Players will interact with games using Microsoft Kinect The game is divided into three main levels, i.e. grade 1, grade 2 and grade 3 . The higher the grade, the degree of difficulty levels and the calculation will be increasingly difficult. Player; Players must choose which egg weighs required according to the target precisely by means of moving the cursor or pointer is controlled by Kinect toward eggs or objects that could be destroyed so that the eggs with the weight required to be entered into the scales. Objective (Goals); The goal of this game is to enter the egg that weighs in the scales and find the combination of egg weight in accordance 
with the total weight of the existing targets. The game will also be given some small obstacles and items to make it more interesting to play. Rules; There are several provisions related to egg weight, egg and obstacle blocking the bonus provisions. Resources and Resources Management; Players can destroy objects such as boxes and bamboo is an obstacle in the game. Game Screen Flow; Display screen is widely groove or activities in this game. Game screen depicted by a rectangle as a state and the direction of the arrows to describe the state or event in the game. Information; tutorial how to play and info via wiki loading. Sequencing; Game Power Egg is designed only to play one person, so there is no turn in playing this game. This game is real-time and the game goes as fast as desired by the player. Theme; Scene in the game Power Egg is about a boy named Leo wants to help her mother to egg shopping. Leo's mother gave money to Leo to buy eggs with the correct change and tell the number of egg weight $(\mathrm{kg})$ to be purchased, so Leo had to gauge how many eggs you have to be purchased in order to fit the number of egg weight. In this game, players play as Leo whose job is to enter the egg that weighs in the scales corresponding required target weight. Players will interact with Microsoft Kinect game. Games as system; this game has no subsystem in it.

Gameplay Consultation is done to experts or people who are experienced in teaching mathematics for grades 1st to 3rd of elementary school. From the games that have been prepared and consulted with and obtained feedback that the game "Power Egg" is good and suitable for children in grades 1 st to 3rd of elementary school.

Iterations are performed in conducting prototyping paper aims to determine the exact gameplay for the game "Power Egg". Iteration on the game "Power Egg" is performed three times, namely; First Iteration; illustrates a sketch of how the power of egg game will be played. The second iteration; the game at this stage is not playable, but it illustrates clearly mechanic game Power Egg. Eggs and barrier can already be moved, move it so that it can explain the gameplay to play tester at the stage of paper prototyping. In the second iteration of players already have rules and questions. The Third Iteration; this stage is already playable. Paper Prototyping is made in the form of egg card that has a value of weight and bubbles as surgery or bonus cards.

The evaluation carried out in order to assess whether the results of the play test met the criteria and objectives that have been set, followed by a decision on the object being evaluated. The evaluation was done by two correspondents from the Laboratory Game of Faculty of Computer Science of Brawijaya University, Malang. The results showed that each play-tester has a record of each evaluation. The first provides that the evaluation Play-tester exciting gameplay for challenges players to hone skills in mathematics. While the second provides two play-tester evaluation notes that the provision of a different color for each number has an interesting mechanic impression and provide suggestions for the power-ups to be more varied in types of calculations. The conclusions obtained from this evaluation is in accordance with the paper prototyping play test that has been provided and evaluated. Thus, game "Power Egg" could have been implemented. Examples Prototyping of egg character shown at Figure 2.

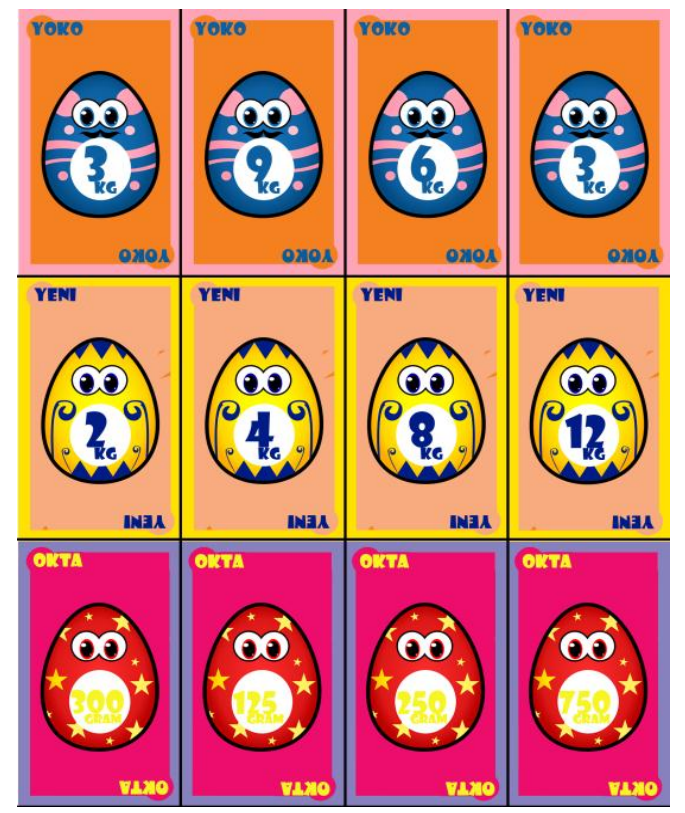

Figure 2. Prototyping of egg character examples 
Implementation of the gameplay consists of program implementation procedures and user interface. This game is made up of a wide range of processes or methods that include: player Interaction Procedure; describes the process that made the player in gameplay that is the implementation of user interaction with the click obstacle. Destroy Obstacle; explains that when the events touch on an object obstacle and the position of not being pause. Obstacle will be destroyed and broken sound and animation rupture. Calculation of Number of Eggs; explains how the calculation of weight gain when there are eggs that go into the scales. Interface design game "Power Egg" implemented several views, the menu 'Home', 'About', 'Loading', 'Gameplay', 'select grade' and 'select level'. The "Home" screen shown at Figure 3.

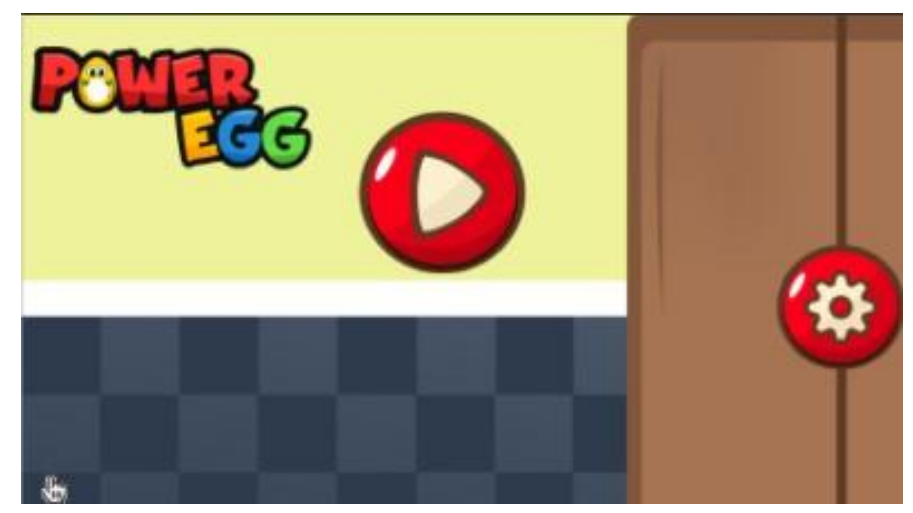

Figure 3. Home screen of Game "Power Egg"

There are twelve levels available in the game for each grade. Each grade has four levels. 1st grade has a problem concerning the calculation of basic addition and subtraction. 2nd grade has a variation of the basic calculations of addition, subtraction and multiplication. In addition to the 3rd grade contained a heavy conversion. "Choose Level" screen shown at Figure 4.

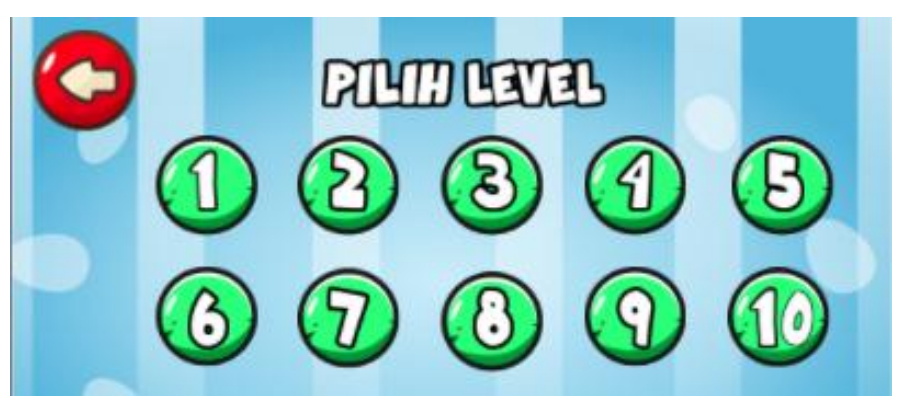

Figure 4. Choosing level

\section{Result and Discussion}

Testing of users conducted in order to determine whether the game "Power Egg" that have been designed and implemented fun and can provide education for children grades 1 st to $3^{\text {rd }}$ of elementary school targets. Tests conducted on 30 students of SDN Penanggungan Malang with a composition of 10 students grade 1 st, 10 students grade 2 nd and 10 students grade 3 rd. Users will be interviewed shortly after playing the game Power Egg. As for the question as follows: is the game fun? (Fun), what is the child's reaction after playing the game? (Usability), and does the game Power egg is hard? (Balance).

An analysis of users against users who are students of SDN Penanggungan Malang grades 1st to 3rd elementary school. Prior tested to the outcome of this game has been consulted and tested prior to the expert who is a mathematics teacher at SDN Penanggungan Malang. From the results of consultations by experts that this game is good enough as a medium of interactive learning. The game testing activity shown at Figure 5 (a) and (b). 
In terms of fun all the children that this play feels happy and $96 \%$ of children want to try the game again. In terms of the other, because it uses a puzzle game some children have difficulty to destroy the obstacle which used to be in order to win the game.

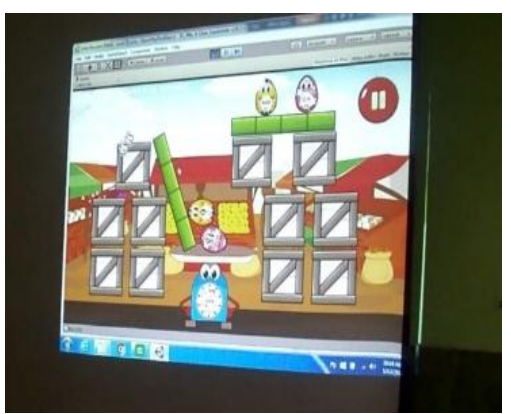

(a)

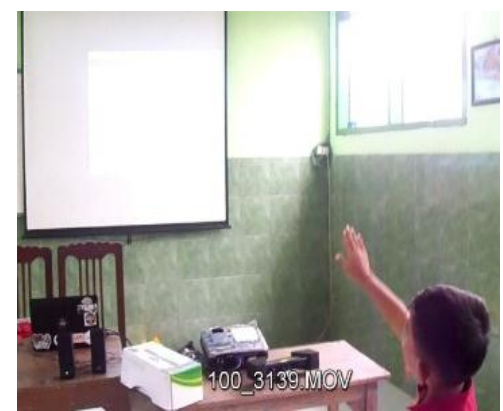

(b)

Figure 5. Play-testing in class

Testing pre and post testing was conducted to determine the effect of the power game Egg before and after the students play. Before playing the game "Power Egg" participants are asked to pre and post testing. Pre-testing is working on the problems given in accordance with the levels. Players will be asked to answer 12 questions that the difficulty level is equal to the design grade level. After pre testing the player is asked to do a post testing. Post testing was given to the participants by the challenge to play two levels appropriate levels.Results of pre-post testing of the game "Power Egg" shows that the average success rate answer questions during the pre-testing was $65.60 \%$. While success in post testing was $74.40 \%$. This proves that when playing the game, the child can solve problems better than just answering math problems that are given.

\section{Conclusion}

The results of tests on the game "Power Egg" obtained some conclusions, i.e.: (1) gameplay of "Power Egg" created by MDA framework had been designed in consult an expert like teacher for grades 1 st to 3 rd of mathematics courses at elementary school, create paper prototype in three times iteration, test and gameplay's evaluation; (2) the functionality and performance of the game is compliant as an interactive media of learning mathematics for grades 1 st to 3rd of elementary school; (3) focus testing concluded that children who have played this game quite happy to play the game Power Egg and want to play it again. Control of the game is also good although there are still some children who are still having trouble because they are new in using the Microsoft Kinect console; and (4) an average rate of successful completion of math problems in examination to thirty elementary students increase up to $8.89 \%$.

\section{References}

Castellar, E.N., All, A., De Marez, L., \& Van Looy, J. 2015. Cognitive abilities, digital games and arithmetic performance enhancement: A study comparing the effects of a math game and paper exercises. Computers \& Education 85: 123-133.

Fitriyeni, Y.H. 2013. Efektifitas Game Edukasi untuk Meningkatkan Kemampuan Penjumlahan bagi Anak Kesulitan Belajar di MIN Koto Luar, Kecamatan Pauh. E-JUPEKhu 2(3).

Hervira, A. \& Yuni, M. 2012. Pusat Tumbuh Kembang Anak. Jurnal Tingkat Sarjana Bidang Seni Rupa dan Desain. Prodi Desain Interior, Fakultas Seni Rupa dan Desain (FSRD). ITB.

Hunicke, R., LeBlanc, M. \& Zubek, R. 2004. MDA: A formal approach to game design and game research. In Proceedings of the AAAl Workshop on Challenges in Game Al 4:1. 